\title{
Who is Better Equipped for Globalization in Eurasia? A Seven-Country Analysis
}

\author{
Tansu Barker, Brock University, Canada
}

\begin{abstract}
Globalization is a long-term transformation of the nation-state that interconnects it to other states. We characterize globalization as a multifaceted concept that has economic, political as well as social dimensions. The countries that are included in this study are Azerbaijan, Kazakhstan, Kyrgyzstan, Tajikistan, Turkey, Turkmenistan and Uzbekistan. In order to make meaningful comparisons and establish a benchmark, we also include Austria as a highly globalized and land-locked country.

The purpose of the study is to provide a measure of the "readiness" of these countries to become more global based on selected economic, political and social variables. With very few exceptions, countries are no longer able to isolate themselves and seek to be self-sufficient. Hence, countries and their governments must accept the reality of globalization and the pressure it creates to look beyond national borders.
\end{abstract}

JEL codes: M16, O53

\section{Facts about Sampled Countries}

The following table attempts to introduce some representative facts that might provide the background to interpret the globalization findings in the rest of the paper. While it is not a comprehensive list of characteristics, the information is meant to cover some of the more pertinent facts regarding globalization.

\begin{tabular}{|l|l|l|l|l|l|l|l|l|}
\hline Variable & Azerb & Kazak & Kyrgyz & Tajik & Turkey & Turkmen & Uzbek & Austria \\
\hline Population & 9.1 & 16.2 & 5.5 & 7.4 & 72.5 & 5.1 & 27.6 & 8.4 \\
\hline Area & 86.6 & 2275 & 200 & 143.1 & 739 & 488 & 447.4 & 83.9 \\
\hline GDP (PPP) & 9564 & 11693 & 2253 & 2103 & 12476 & 5971 & 2806 & 38839 \\
\hline GINI & 36.5 & 28.8 & 30.3 & 32.6 & 41 & 40.8 & 36.8 & 26 \\
\hline Urban \% & 52 & 58 & 36 & 26 & 69 & 49 & 37 & 67 \\
\hline HDI & .787 & .804 & .710 & .688 & .806 & .739 & .710 & .955 \\
\hline Exports & 38.3 & 66.6 & 1.7 & 1.4 & 111.1 & 9.9 & 10 & 137 \\
\hline Vulnerabil. & 5.4 & 4.6 & 6.3 & 6.3 & 7.5 & 5.4 & 4.6 & 1.3 \\
\hline Democracy & 3.31 & 3.62 & 4.08 & 2.45 & 5.7 & 1.83 & 1.85 & 8.69 \\
\hline
\end{tabular}

\section{Table 1 - Country Statistics}

The countries included in this paper represent much diversity in terms of their size, economic and social characteristics. Therefore, the tentative conclusions presented in this paper should be taken as a starting point for what might be a promising approach rather than indisputable conclusions. Future refinements in the selection and weighting of the variables used in this study are expected to improve the results considerably.

These countries exhibit significant diversity along economic, political and social dimensions. Therefore, extreme care must be exercised in interpreting even index numbers that provide a certain degree of protection over comparing absolute figures across the seven countries. Next, we provide brief comments about each country (Wikipedia, 2010) to supplement Table 1 where HDI is a function of life expectancy, education and standard of living and Gini coefficient is a measure of the inequality of distribution of income, a value of 0 expressing total equality and 1 maximal inequality.

Azerbaijan: It is a secular presidential republic established in 1991. Approximately $95 \%$ of 
the population of Azerbaijan is Muslim. Rich in oil and natural gas, Azerbaijan is considered to be important in terms of oil exploration and development. It is a member of IMF.

Kazakhstan: Landlocked country is the ninth largest in the world. Sixty-three percent of the population is Kazakhs with $24 \%$ Russians. Kazakh and Russian are the official languages. While it is an important exporter of uranium and rich in mineral deposits, crude oil and natural gas lead the economy.

Kyrgyzstan: Parliamentary republic where $69 \%$ of the population are Kyrgyz, $14 \%$ are Uzbek and 9\% Russian. Agriculture is the leading economic activity with substantial mineral reserves. It exports hydroelectric energy but imports oil and gas.

Tajikistan: It is a presidential republic that shares language, culture and history with Iran and Pakistan. The economy is dependent on cotton and aluminum. Despite its modest economic means, the literacy rate is estimated to be $99.5 \%$.

Turkmenistan: It possesses the world's fourth largest reserves of natural gas resources and is the tenth largest grower of cotton. The ethnic composition of Turkmenistan is $85 \%$ Turkmen and $89 \%$ are Moslems. Its debt burden, level of poverty, unemployment and limitations on "freedoms" present difficulties.

Uzbekistan: It is a presidential republic where $80 \%$ of the population is Uzbeks. Economy relies mainly on cotton, gold, uranium, potassium and natural gas. Import substitution is an officially declared policy. Uzbekistan has a 99.3\% literacy rate among adults older than 15 and $34.1 \%$ of its people are younger than 14 .

Turkey: It is a democratic, secular, constitutional republic. Given its strategic location, large economy and army, Turkey is classified as a regional power and is a member of G-20. It is the fourth largest ship building country in the world. Other key sectors of the economy are banking, construction, home appliances, textiles, petrochemical products, food, mining, iron and steel, machine industry and automotive. Only $7 \%$ of the population is older than 65 years old.

Austria: It is a federal parliamentary republic. It is one of the richest countries in the world. Austria produces $63 \%$ of its energy through renewable sources and has banned nuclear stations. $74 \%$ are Roman Catholics and $89 \%$ are native Austrians speakers. It has a highly developed social market economy with strong labor unions.

\section{Dimensions of Globalization}

Defining globalization is not a straight forward matter. While the debate continues and there is certainly no unanimity, business people tend to associate globalization with lowering of trade and cultural barriers whereby national markets move toward merging into more similar markets. Marketers talk about global marketing strategy in terms of a single strategy for their offerings for the entire global market with the proviso that modifications must be made to accommodate environmental differences. One popular textbook (Hill and McKaig, 2009, p.9) defines globalization as "the shift toward a more integrated and interdependent world economy". This approach generally depicts globalization in a favorable light and links it to improvements in economic welfare.

Others (Bevan and Gitsham, 2009) suggest a sociological approach that seems to challenge these favorable certainties and points toward far less organizational security. They claim that the sociological approach to globalization appears to have been more accurate at predicting the complexity of globalization than an economic approach. The sociological approach may be understood as the increasing interdependence of world society such that what happens on the other side of the world affects us directly in an immediate way far more profoundly than in previous generations (Giddens, 1999). Parker (1999, pg. 234) suggests that globalization is experienced subjectively as a "growing sense that events occurring throughout the world are converging rapidly to shape a single integrated world where economic, social, cultural, 
technical, business, and other influences cross traditional borders and boundaries such as nations, national cultures, time, space and industries with increasing ease". On the other hand, Martens, et. al, (2010) argue that "socio-cultural factors not only change as a result of globalization, but also can be causes, as well as challenges to the process of globalization itself".

Dorn (2009) contends that "the fundamental determinant of development is not natural resources or capital investment but the choice of institutions, which depends heavily on the government's development strategy". This is a crucial way of portraying globalization beyond the traditional economic or business perspective that emphasizes the political and social aspects. In considering the impact of political influence on globalization, we can broadly separate the governments into two groups, namely, those pursuing export promotion versus import substitution. Justin Lin (referenced in Dorn, 2009) calls the import substitution strategy "a comparative-advantage-defying (CAD) strategy" whereby the fastest way to catch up with developed countries was to employ Soviet-style planning, raise trade barriers and protect infant industries. This perspective that has been quite influential in many of the countries included in the current study highlights the importance of paying particular attention the political dimension of globalization.

Based on the previous discussion, we have fashioned our study after the KOF model (Dreher, 2006) that treats the economic, political and social dimensions of globalization separately as presented in Table 2. The KOF (2009) model employs a weighted average approach where the weights assigned to the economic, political and social dimension are $38 \%, 23 \%$ and $39 \%$, respectively. Next, we provide a brief description of the methodology used to calculate each dimension.

\begin{tabular}{|l|c|c|c|c|}
\hline Country & Globalization & Economic & Political & Social \\
\hline Azerb & $55.2(4)$ & 58.8 & 55.6 & 51.3 \\
\hline Kazak & $60.8(2)$ & 69.8 & 67.8 & 48 \\
\hline Kyrgyz & $59(3)$ & 61.2 & 67.5 & 51.5 \\
\hline Tajik & $34.5(7)$ & 34.8 & 43 & 29.2 \\
\hline Turkey & $64.9(1)$ & 64 & 93 & 48 \\
\hline Turkmen & $38.7(6)$ & 38.7 & 38.4 & 38.9 \\
\hline Uzbek & $40.3(5)$ & 40.6 & 45.7 & 36.8 \\
\hline Austria & 92.5 & 89.3 & 96.9 & 92.8 \\
\hline Bulgaria & 75.4 & 84.1 & 87.6 & 59.5 \\
\hline Romania & 71.5 & 75.1 & 92.4 & 55 \\
\hline ASIA & 61.9 & 61.9 & 62 & 50.9 \\
\hline
\end{tabular}

Table 2 - KOF Indexes

Economic globalization is based on "flows" such as trade as percentage of GDP, foreign direct investment and "trade restrictions" such as import barriers and import taxes. Equal weight is assigned to flows and trade restrictions in calculating the economic globalization index.

Social globalization includes personal contact (34\%) through telephone traffic and foreign population, information flows (34\%) including TV and internet usage and cultural proximity (32\%) based on number of IKEA, McDonalds outlets and trade in books. Martens et. al,. (2010) make the critical observation that "socio-cultural factors not only change as a result of globalisation, but also can be causes, as well as challenges to the process of globalisation itself".

Political globalization is based on embassies in the Country $(25 \%)$, membership in international organizations (28\%), participation in U.N. Security Council Missions (22\%) and international treaties $(25 \%)$. 
Clearly, the indices include many subjective preferences both in the variables used to operationalize certain concepts as well as the weights that are assigned to them. We employ these and other data with caution and the caveat that the choices made may not have the same impact on every country. Hence, it is more appropriate to look at the relative positioning of the countries rather than the absolute figures that are calculated.

Globalization is not a panacea for advancement and has its share of criticism. Globalization has the potential to allow powerful countries to overrun the cultural, economic and political systems of smaller and less powerful countries leading to Americanization, McDonaldization or creolization of the world. Critics of globalization call for more transparency, egalitarianism, respect for human rights, dignity, the environment and fair trade.

\section{Alternative Globalization Index Calculations}

The overall globalization index calculated by Dreher (2009) based on the relative weights of $38 \%, 23 \%$ and $39 \%$ assigned to the economic, political and social indexes produces the results presented in the second column of Table 2.

\begin{tabular}{|l|c|c|c|c|}
\hline Country & $\begin{array}{c}\text { Globalization } \\
\text { Index }\end{array}$ & Econ. Driven & $\begin{array}{c}\text { Politically } \\
\text { Driven }\end{array}$ & $\begin{array}{c}\text { Socially } \\
\text { Driven }\end{array}$ \\
\hline Azerb & $55.2(4)$ & $56.8(4)$ & $56.1(4)$ & $54.1(4)$ \\
\hline Kazak & $60.8(2)$ & $66.8(2)$ & $66.4(2)$ & $58.3(2)$ \\
\hline Kyrgyz & $59(3)$ & $62.8(3)$ & $64.0(3)$ & $58.2(2)$ \\
\hline Tajik & $34.5(7)$ & $37.5(7)$ & $39.2(6)$ & $34.5(6)$ \\
\hline Turkey & $64.9(1)$ & $74.0(1)$ & $79.8(1)$ & $64.7(1)$ \\
\hline Turkmen & $38.7(6)$ & $38.6(6)$ & $38.5(7)$ & $38.7(7)$ \\
\hline Uzbek & $40.3(5)$ & $42.3(5)$ & $43.3(5)$ & $40.2(5)$ \\
\hline Austria & 92.5 & 92.7 & 94.2 & 93.3 \\
\hline
\end{tabular}

Table 3 - Globalization Indexes

Our discussions with colleagues and business leaders suggested quite strongly that the three weights used to generate the KOF globalization index (Table 2, col. 2) are worthy of further consideration. In particular, the point that was made strongly was that the environmental context of different countries may shift the balance of power from one of the dimension of globalization to another. Prompted by these discussions, we have undertaken to calculate several additional globalization indexes to investigate the political, social and economic components of the overall globalization index. Therefore, we present the following three scenarios:

Scenario I, Globalization driven by Economic Factors: The traditional approach to studying globalization from the business perspective is to assign more importance to economic factors that allow a country to be more competitive and to interact with other countries. In this scenario, we assigned a weight of $50 \%$ to the economy. The remaining weights are $40 \%$ political and $10 \%$ social. The reasoning is that, especially, in developing countries the political landscape is likely to be far more influential than the social factors. A higher weight assigned to the economic factors may be seen to suggest a weaker link between the economic and political than might be expected realistically in this group of countries. The results are presented under column 3 of Table 2 .

The relative rankings of the countries remain unchanged compared to the KOF overall globalization index. Turkey is still at the top of the list with Tajikistan having the lowest propensity to globalize based on emphasizing economic factors. While six of the seven countries have improved their index under this scenario, the fact remains that there is a big apparent gap between them and other developed countries as represented by Austria.

Scenario II, Globalization driven by Political Factors: The weights of the political, 
economic and social factors are $60 \%, 30 \%$ and $10 \%$, respectively. While the order of the top five countries remains the same, Tajikistan and Turkmenistan switched places at the bottom. Turkey appears to have a higher political will to become more globalized ahead of its economic potential. To a lesser degree the same observation applies to Kyrgyzstan, Uzbekistan, Tajikistan and Austria. This observation lends mild support to the view that political factors might be as important as the economic factors and may be somewhat more in certain countries.

Scenario III, Globalization driven by Social Factors: In this scenario, social factors have a weight of $50 \%$, followed by $30 \%$ political and $20 \%$ economic factors. The rankings are consistent with the previous scenarios. However, six of the seven countries have lower social indexes compared to their own political and economic indexes. Furthermore, the gap with Austria has widened here considerably. This raises the potentially crucial question of the balance between the three sets of factors in terms of readiness to become more global. Can weaknesses in one area be compensated by strengths in other areas?

We conducted a second analysis under this scenario by switching the weights of political and social factors to $20 \%$ and $30 \%$, respectively. The rankings did not change at all. The absolute magnitude of the revised index changed by less than 1 point for seven of the eight countries. The only notable change was for Turkey (64.7 down to 61.8) when the weight of the political component was reduced to $20 \%$ as a result of its high (93) value.

We included the two newest members of EU, Bulgaria and Romania, as a further point of reference. Compared to Bulgaria and Romania, only Turkey exceeds Bulgaria in terms of its political index. Given that these two countries are not considered to be powerhouses of globalization, the Eurasian countries have to make significant improvements socially, politically and economically. As an example, the ten countries that joined the EU in 2004 present consistent indexes with an average globalization index of 80.4. The Vulnerability Index (Table 1) also highlights the need for better balance as it is a blended measure of various economic (Gini), political (unrest, trust) and social (ethnic fragmentation) indicators.

Recognizing that comparisons against other Asian countries might be more meaningful, we calculated average indexes for Asia excluding the seven countries of interest. Turkey does better in all areas except the social index that is slightly lower. Kazakhstan is ahead of the Asian average economically and socially. Kyrgyzstan only has a higher social index. The results do not favor the Eurasian countries.

In conclusion, the Eurasian countries have much ground to cover and significant progress to make regarding all aspects of globalization. Azerbaijan, Tajikistan, Turkmenistan and Uzbekistan are behind the Asian average in all categories and face significant challenges if they wish to embrace globalization. Kazakhstan and Kyrgyzstan have certain advantages behind Turkey. However, their achievements and potential in certain areas of globalization seem to be mitigated by a lack of consistent performance in other areas. The indisputable fact remains that, as exemplified by Austria, even Bulgaria and Romania have achieved a higher level of consistency and uniform performance along globalization dimensions except the social index, which is still higher than the Eurasian countries. The fact remains that out of 195 countries included in the KOF index; only 21 have a social index greater than $80 \%$ with Switzerland leading the pack at $95 \%$. Singapore has the highest social index in Asia at $79.9 \%$. Perhaps, Bevan and Gitsham (2009) are right in stating the "sociological approach to globalization appears to have been more accurate at predicting the complexity of globalization than an economic approach". 


\section{References}

- Bevan and Gitsham, 2009. "Context, Complexity and Connectedness: Dimensions of Globalization Revealed", Corporate Governance, 9, p. 435.

- Dreher, 2006. "Does Globalization Affect Growth? Evidence from a New Index of Globalization", Applied Economics, 38, p. 1091.

- Dorn, 2009. "Economic Development and Transition: Thought, Strategy, and Viability, Cato Journal, 29, p. 600.

- Hill and McKaig, 2009. Global Business Today. McGraw-Hill, New York. 2. Canadian. Ed.

- KOF, 2009. Globalization Index, http://globalization.kof.ethz.ch.

- Martens et. al, 2010. "Globalisation, the Global Village and the Civil Society", Futures, 42, p. 575.

- Parker, 1999. "Evolution and Revolution: From International Business to Globalization", in Clegg, S.R., Hardy, C. and Nord, W.R. (Eds), Managing Organizations: Current Issues, (1999), Sage, p. 234.

- Wikipedia, 2010. http://en. Wikipedia.org/wiki/country name. 